Saudi Journal of Humanities and Social Sciences

Abbreviated Key Title: Saudi J Humanities Soc Sci

ISSN 2415-6256 (Print) | ISSN 2415-6248 (Online)

Scholars Middle East Publishers, Dubai, United Arab Emirates

Journal homepage: https://saudijournals.com/sjhss

Review Article

\title{
Ethnic Identity Politics and Contemporary Experience
}

\author{
Dr. Sarah Terwase Shittu , Ogbedu Michael
}

Benue State University, Makurdi, Nigeria

DOI: $10.36348 /$ sjhss.2020.v05i03.005

| Received: 16.03.2020 | Accepted: 24.03.2020 | Published: 27.03.2020

*Corresponding author: Dr. Sarah Terwase Shittu

Abstract

This paper investigates the complex developments of identity in contemporary Africa considering that the emergence of identity politics is a consequence of the extraordinarily rapid and profound upheavals and transformations of human society at the turn of the $21^{\text {st }}$ century. Contemporary world has considerably opened up and extraordinarily shrunk in specific historical circumstances. The act of migration particularly, is one that profoundly changes the individual, transforming the relationship of the migrant with his home country and new host country and then impacting their identity as a result. The expanding use of the term, identity politics, is scrutinized in this work and attempts are made at delineating its unwieldy parameters. This in turn reflects the socio-political composition of African societies.

Keywords: developments, contemporary, migrant, identity politics.

Copyright @ 2020: This is an open-access article distributed under the terms of the Creative Commons Attribution license which permits unrestricted use, distribution, and reproduction in any medium for non-commercial use (NonCommercial, or CC-BY-NC) provided the original author and source are credited.

\section{IDENTITY}

The term identity is a rather broad one encompassing, in the context of this paper, self and communal definitions of people based on ethnicity. Thus, the term is essentially comparative in nature as it emphasizes the sharing of a degree of sameness or oneness with others in a particular area or on a given point. It is best construed as both contextual and relational. The formation of one's identity occurs through one's identification with significant others and also with groups as they are perceived. Ethnic identity politics should thus be taken to mean political ideology, organization, and action which openly represents the interests of designated groups based on essential characteristics such as ethnic origin or religion and whose legitimacy lies in the support of important segments of such groups [1-4].

\section{Ethnicity}

Ethnicity is the property of the relationship between two or several groups, not a property of a group; it exists between and not within groups. It is the enduring and systematic communication of cultural differences between groups considering themselves to be distinct. It appears wherever cultural differences are made relevant in social interaction, and it should then be studied at the level of social life, not at the level of symbolic culture. Ethnic politics was birthed as a result of colonialism, and later compounded by post colonialism. Ethnicity as a vestige of colonialism is prominent in the social relations of the African countries such as Rwanda, South Africa, and Kenya [5, 6].

A sense of ethnic identity is developed from shared culture, religion, geography, and kinship as well as proximity. In Helms's words, these are aspects that make up learned culture include rituals, symbols, and behaviour that manifest themselves from underlying values, beliefs, and assumptions. Deep conscious immersion into cultural traditions and values through religious, familial, neighbourhood, and educational communities instils a positive sense of ethnic identity and confidence. (12) Ethnicity is thus relational and also situational: the ethnic character of a social encounter is contingent on the situation. It is not in other words inherent. Theorists of nationalism and ethnicity have pointed out that identification is relational, situational and flexible and that each person carries a number of potential identities, only a few of which become socially significant making a difference in everyday life. Ethnicity is a politically relevant signifier in contemporary Africa. This paper reveals how ethnic communities can both contract or expand and how actors and groups can draw on selective memories and histories to justify their migration from one community to another while the relevant content of ethnic units is open to both debate and contestation. The study provides detailed evidence of the fact and nature of ethnic construction, deconstruction and creation in 
the African post colony and reveal how processes of ethnic negotiation and renegotiation are ultimately fuelled by the desire to stake claims to, and access resources controlled by Africa and external agents. Ethnic identities are best understood as complex and contested social constructs, perpetually in the process of creation. Issues of ethnic identity continue to be of great importance in politics both in Africa and globally [7].

Individuals who constitute an ethnic group share a sense of group identification, a common set of values, political and economic interests, behavioural patterns, and other culture elements that differ from those of other groups within a society. According to Peter Rose, groups whose members share a unique social and cultural heritage passed on from one generation to the next are known as ethnic groups. They are frequently identified by distinctive patterns of family life, language, recreation, religion and other customs that cause them to be differentiated from others. (13) An individual is ethnic to the extent that he or she shares the values, behavioural patterns, cultural traits, and identification with a specific ethnic group identify its members easily [8].

\section{Assimilation and Acculturation Acculturation}

Acculturation proceeds in both directions when two societies are in any kind of contact, and that even a conquered people help to shape the destiny of their overlords. Most Africans grow up in communities in which ethnic and cultural values, life-styles, language patterns and behavioural patterns differ from those of many other groups. Because most Africans grow in ethnic or cultural enclaves, they are culturally encapsulated. Ethnic minority groups, in order to attain social and economic mobility are usually forced out of their ethnic encapsulation. The cultures of other groups remain foreign, non-human, and exotic to them. When two ethnic groups are exchanging cultural elements and complexes, acculturation is taking place. Thus, it is a cultural change resulting from direct contact between two cultural groups.

\section{Cultural Assimilation}

When a member of an ethnic minority group acquires the behaviour patterns, life-styles, values and language of the mainstream culture, we say that he or she has become culturally assimilated. It is the process by which an individual or group acquires the culture traits of a different ethnic or cultural group. Because the dominant group controls most of the social, economic and political institutions in a society, members of ethnic minority groups must acquire its cultural traits to move up the social and economic ladder. It must be noted that although a people may become totally assimilated culturally, they will still be victims of discrimination because of their different physical characteristics.

\section{Ethnic Identity}

Ethnicity is a term that has been used increasingly since the 1960 s to account for human variation in terms of culture, tradition, language, social patterns, and ancestry, rather than the discredited generalizations of race with its assumption of humanity divided into fixed genetically determined biological types.(80) According to Schermerhorn Eric, 'ethnicity refers to the fusion of many traits that belong to the nature of any ethnic group; a composite of shared values , norms, tastes, behaviours, experiences, consciousness of kind memories and loyalties.(2) Invariably, a person's ethnic group is such a powerful identifier because while he or she chooses to remain in it, it is an identity that cannot be denied, rejected or taken away by others. Membership of an ethnic group is shared according to certain agreed criteria, even though the nature, the combination and importance of those criteria may be debated or may change over time.

Ethnic identity has been described by Alicia Chavez as a critical part of an overall framework of individual and collective identity which is manifested in very conscious ways. This manifestation is triggered most often by two conflicting social and cultural influences. Firstly, deep conscious immersion into cultural traditions and values through religious, familial, neighbourhood and educational communities instil a positive sense of ethnic identity and confidence. Secondly, and in contrast, individuals must filter ethnic identity through negative treatment received from others because of their ethnicity. By this, people with a minority status have a different ethnic make-up and one that is less desirable within mainstream society. For others ethnic identity is manifested mostly in unconscious ways through their behaviour, values, beliefs and assumptions. To them ethnicity is unconscious and referred to as such because societal norms have been constructed around their ethnic and cultural frameworks, values and priorities and then referred to as ethnic identity. Chavez emphasises that everyone benefits from the development of a conscious ethnic identity.

Bill Ashcroft argues that the element of marginalization in ethnicity in its earliest uses remain implied even in contemporary usage. Originally, it referred to heathen nations and now is suggestive of groups that are not mainstream, that are not traditionally identified with the dominant national mythology which is not limited to colonial experience but does reveal the imperialistic nature of national mythology and the implications of any link between ethnicity and nation. (82) Recent studies reveal that ethnic groups are not necessarily marginalized and cultural groups but all ethnic groupings since the concept of ethnicity itself has come to exert a powerful political function. This means that regardless of the status of the particular group, its ethnicity is a key strategy in the furtherance of group political interests and political advancement. Even 
though group power is seemingly always a favoured solution to individual powerlessness, the ethnic group is a salient formation in the bid for political power within a society. (83)

Given the fact that ethnicity comes into greatest contemporary currency in the context of immigration, Isajaw further defines ethnicity in its contemporary usage as 'a group of persons who have a common ancestral origin and the same cultural traits, who have a sense of peoplehood and of group belonging, who are of immigrant background and have either minority or majority status within a larger society.(118)

Similarly, Waters M.C. considers ethnic identity as a social construct: 'an individual's identification with a segment of a larger society whose members are thought by themselves and others to have a common origin and share segments of a common culture and who, in addition, participate in shared activities in which the common origin and culture are significant ingredients. (200) Ethnic identity is a conscious or unconscious identification with those with whom they feel a common bond because of similar traditions, behaviours, values and beliefs. Ott asserts that, it is these points of connection that allow individuals to make sense of the world around them and to find pride in who they are. (41) In essence, ethnic identity models provide a theoretical structure for understanding individual's negotiation of their own and other cultures.

Most models of ethnic identity trace their roots to the psychological research of Erik Erickson or the cognitive structural work of Jean Piaget. Curiously, all identity models focus on the psychological process of defining the self; some also acknowledge the cognitive complexity of the self definition process. The traditional models in both categories are stage models in which growth occurs in a step-wise progression whereas contemporary models describe ethnic identity as a process that occurs over a lifetime. These models focus on what people learn about their culture from family and community. In other words, a sense of ethnic identity is developed from shared culture, religion, geography, and language of individuals who are connected by strong loyalty and kinship as well as proximity. (42) It is critical to note that ethnic identity affects the experience with and interpretation of relationships with others.

Fearon and Laitin define ethnicity in terms of three aspects: A common descent, conceptual autonomy, and a common history. One and three above are very common among definitions of ethnicity. The conceptual autonomy roughly corresponds to whether a group is defined by its internal attributes or in opposition to another such group since it comprises an attempt to exclude certain groups like Tutsis and Hutus in Rwanda. Ethnic characteristics as belief in a common descent can and does change over generations and centuries. Elliot Green proposes a definition of ethnicity that is based on three core elements; common descent, a common history, and a common homeland. This definition is quite flexible as it allows for continuity and change: a variety of interpretations of ethnicity such as primordialism and constructivism while also allowing for a means to differentiate ethnic groups from other communal groups like castes, nations, and races.

Roger Ballard attempts an identification of how ethnicity is used in current popular discourse and how it can be defined in technical terms such that they can be turned into more precise and more effective vehicles for sociological analysis. He explains further that ethnicity

Is the outcome of the articulation of cultural distinctiveness in situations of political and/or economic competition. As a result it normally erupts in response to patterns of inequality of one form or another. Hence, just as privileged groups routinely close ranks in ethnic terms to exclude their social subordinates in the hegemonic patterns... the excluded frequently respond by closing ranks themselves, the better to resist and subvert their subordination. When each side reacts in turn against the other, the outcome is very often a rapid and escalating process of mutual ethnic polarisation.(28)

Thus, it follows that those at the top of the social order routinely close ranks in order to sustain their position of privilege while those at the bottom have a parallel interest in closing ranks the better to resist the exclusionary pressures to which they are subjected. In order to encompass the variety and complexity of social and cultural features constituting ethnicity, Schermerhorn Eric has developed a more elaborate definition of the term to mean

A collectivity within a larger society having real or putative common ancestry, that is memories of a shared historical past whether of origins or of historical experiences such as colonization, immigration, invasion, or slavery, : a shared consciousness of a separate, named, group identity; and a cultural focus on one or more symbolic elements defines as the epitome of their peoplehood. These features will always be in dynamic combination, relative to the particular time and place in which they experience and operate consciously or unconsciously for the political advancement of the group.

From this definition, it is evident that ethnic identities go beyond the limits of cultural assimilation into the wider society and the persistence of ethnic identity is not necessarily related to the perpetuation of traditional cultures. No ethnic group is completely 
unified or in complete agreement about its own ethnicity and no one essential feature can ever be found in every member of the group. However, this dynamic interweaving of identifying features has come to function as increasingly potent locus of identity in an increasingly migratory, globalized and hybridized world.

\section{SYNOPSIS OF WEIGHT OF WHISPERS}

Weight of Whispers is narrated by the story's central character, Boniface Louis R. Kuseremane, a refugee, who seems already to have become, in the few journalistic mentions of the story, a "Rwandan Aristocrat" of Tutsi origin. He moves with his immediate family to the archetypal postcolonial African city, Nairobi, as he flees the turmoil in his home country Rwanda. This is on the fifth day, following the assassination of the Presidents of Rwanda and Burundi.Kuseremane slips further into identity crisis and squalor in an unwelcoming foreign land, eventually ending up in total anonymity and debilitation. He is a cross-border refugee (124). Aspects of his precise origins remain elliptical and indeterminate.

He takes with him his mother, Agnethe-Mama, Lune his wife, and Chi his sister with $\$ 3,723$ and a few belongings. The embassy is closed and there is no way to arrange for travel papers to Europe. He soon runs out of money when he hires a first class hotel for the family, escapes and they go to rent a one-room apartment, obviously to save money. His friends abandon him. His efforts to register with the local United States office are met with frustration as corrupt officials are demanding for huge sums of money. Eventually, he gets registered. Kuseremane is a well educated man with a PhD in Diplomacy and a Masters in Geophysics. (16) It is unbelievable to him that with his level of education, he and his family are refugees. Sleep abandons him as they move from one apartment to another. Chi-chi becomes pregnant by an Ethiopian. She dies due to over bleeding. Agnethe-mama dies a day before they are supposed to leave for Canada. Lurie leaves for Canada thinking her husband will join her soon but he stays back to take care of the graves. The short story is one about good and evil, injustice and betrayal, love and loss, the mere struggle of living-ofexistence in the context of contemporary ethnicity-laced post-colonial society.

\section{ACOUSTIC METAPHORS AS FEATURES OF STYLE}

The title of the short story Weight of Whispers itself is implied. It appeals to the reader's acoustic channel and also creates a strong connection between the related words and their meanings. The story is permeated with this stylistic device and examples include, inter alia: "Langora-Leopard" (p. 27), "hacking-hedge" (p.20), "dribs-drabs" (p. 30). The reader can therefore visualize the issues being referred to easily. There are also combinations of assonance and onomatopoeia_ “clock-clicks" (p. 19), “cracks knuckles... Crack. Crack (p. 22). In this instance, the use of onomatopoeia underscores the policeman's act of superiority over the protagonist, eventually harming him.

\section{Leitmotifs of Silence, Noise and Water}

Examples of Leitmotifs abound in Weight of Whispers. Silence, Noise and Water are prominent. Kuseremane's silence is necessary in order for him to get the whispers that haunt him and connect him to the genocide back in his home country. Whispers are a sign of the process that later leads to the mental degeneration, and paradoxically, character development of the protagonist as he descends into guilt. $\mathrm{He}$ is a suspect in the genocide that has just happened in his country, Rwanda and is currently on the run to Europe via Nairobi where he needs his papers processed first. Through whispers of his fellow countrymen in Nairobi, Louis Kuseremane is linked to the famous assassination of the two presidents of Rwanda and Burundi; a historical fact that scholars agree triggered the Rwandan Genocide of 1994. No doubts these whispers cause unease in the mind of the protagonist which invariably develops the plot of the story. He himself confesses that, "whispers like mist floated over the land of hills and nestled in valleys and refused to dissipate" (23). There is a strong link between the Whispers which cannot be stopped or kept away and nature- as well as the mist that disappears and then never fails to return another day. Among crowds of suspicious Rwandese countrymen in Nairobi, these whispers are heard. They are however, afraid to confront the truth and discuss about it but prefer to hide their opinions "in the noise" of the busy city. (23) Seemingly, majority of these people avoid the silence.

The omnipresent leitmotif in this short story is water. Being one of the four elements (water, air, fire, and earth) it has always played an important role in Literature across culture and generations. Like William Shakespeare, who used water to foreshadow the death of his characters, Owuor does same. She has used rain and thunder to foreshadow a "strange foreboding" in Kuseremane as the author in this case has taken this further. Beyond this attribute, water reflects the outer and inner world of the characters and their states of mind. It reflects them each to the other when we see it as part of the mirror that is their eyes as they sit in silence.

More overt connections between water and metaphorical usage as is the case when the element is directly linked to descriptions of humans; "... the crowds dribble" (22) or "the rivers of workers . .." (32) The entire country of exile, Kenya is linked to water when Kuseremane describes it as "the watermark of the map of Kenya." (22) On the other hand, water is personified and given human attributes in its "feeling of anger." (29)Owuor intends to underscore the fact that 
humans and nature do not only influence each other but are directly connected to each other. For instance, it is in this way that water in the form of rain can be interpreted as a metaphor for sorrow when Kuseremane, after another unsuccessful day changes travel plans in order to leave Nairobi for Europe with his family, walks home crestfallen as it rains heavily, down the famous River Road. (23) We get to know from the short story that water which ironically should be a metaphor of hope and rejuvenation "has seeped into his bones and become ice (19) The irony helps to underscore the upside-down nature of the story and enables us to see this tale of a royal family in exile, accused of political crimes that no one can really prove they committed. We can also see the reliability on language and theme to touch on the big social issues that the author seeks to highlight.

The juxtaposition of certain leitmotifs serves well in the deployment of style and thematics. Foreshadowing and flashbacks actually rely on the effective nature in which imagery is used in Weight of Whispers. Imagery draws attention to the major themes of the story that would be discussed in the next subsection.

\section{Human Evil as Major evil}

Human evil is central in Weight of Whispers and Kuseremane is the bearer of this message. He reveals, in the opening of the short story, while reminiscing about a dialogue with a friend. He says, "I had agreed to offer perspectives on his seminal work, a work in progress, he called, "A Mystagogy of Human Evil." (13) The protagonist, Kuseremane comments on the evil deeds committed against him and his family by the unscrupulous police officers and other ignorant people in authority. His own deeds on the other hand communicate reflections at the beginning of the story provides insight into the evil within: "Later on, much later on, I will wonder what makes it possible for one man to hit another for no reason other than the fact that he can." (12) At this point, he is commenting on police brutality. The protagonist did not consider humans to be quintessentially evil as long as they belong to the privileged social stratum. However, the family is let down by former friends, they are betrayed in money matters. The women have to indulge in prostitution in order to be allowed to immigrate to Canada. Clearly, human beings short-change other powerless humans; they even enjoy the power they have over others.

Kuseremane says "there is even an oblation of men by men to men." (13) While people try to silence the atrocities by men to men, they still exist and will always exist because ". . . [Human] nature relishes fratricidal blood." (14) There is the constant interrelation of the evil within and the evil around. By the end of the story Kuseremane finds himself in a hopeless situation, stripped of even the ground that he used to stand on. Right up to the end, the vindictive whispers; the weight of the guilt within remain present and come with a vengeance that exceeds Kuseremane's death. In essence, the protagonist is paying for the evil he has done. He has paid with the eventual loss of his family, psychic suffering, the weight of his overgrowing guilty conscience and the knowledge that the threatening suggestions will not fall silent until he dies. Owuor's short story communicates a strong moral lesson along the lines of "You reap what you sow". The initial catalyst of his downfall was one of Kuseremane's evil deeds that landed his family and the lives of hundreds of thousands of lives in doom.

\section{The Predicament of Refugees in Exile}

This subsection will analyze the situation of refugees in exile with a particular character; Louis Boniface Kuseremane. First, he tries to ignore the precarious situation, then makes attempts at escaping or in the least adapt to it but in the end, he collapses. He is almost certain that he and his family will leave Nairobi, Kenya very soon. Thus, he does not really see himself as a refugee but a visitor to Kenya; a situation that eventually renders him status-less. When we first meet him he is a prince with many contacts all over the world, and not a beggar, who is let down by friends ( $\mathrm{p}$. 17). As refugees he and his family do not enjoy any rights but are rather exposed to the arbitrariness of the Kenyan people and the bureaucracy. They are in constant threat of being arrested for nothing. After several attempts, they finally obtain a Refugee Registration Number which at least, allows them a legal officially acknowledged presence in Kenya. This, however, does not guard them against further harassment on the part of the police and the officials nor does it help them in getting work.

One of the most important parts of the book concerning the situation of refugees in exile is a flashback which Boniface has of a scene in a café in the Netherlands back in times when he still was a successful businessman. A Sierra Leonean who had a Master's degree in sociology but then sold under wears, came up to him and said: "Africans, we be overeducated fools ... no one sees your knowing when you has no facts to stand in." (25) Back then, Kuseremane was ashamed of the man in front of inn Dutch business partners, probably even disdained him. Sadly, in Kenya, he is almost in the same situation as the man from Sierra Leone and now understands the truth of the man's words. He realizes that in exile, we lower our heads so that we do not see in the mirror of another's eyes, what we suspect about ourselves: that our precarious existence depends on the whim of another's tolerance of our presence." (25) This can be seen as the seen as the bottom line of the situation of refugees in exile. The family cannot obtain work. They are almost deprived of their right. Their lives are dependent on the goodwill and tolerance of others. Your educational attainment and connections are really of no use once one leaves his home country. What that 
means is that once one loses his authority, he is stripped of his existence and has to depend entirely on another's authority and existence. Thus, the first lesson in exile is to camouflage. (28) It is of utmost importance to know when to say what and to whom. A careless word to the wrong person can send someone to the prison. It is rare to find trusted friends in exile because just about everyone is restless, scared and alert. In fact, it is not even important who you are.

\section{The Weight of the Whispers}

When the rumours of the Genocidaires start, the situation of the Kuseremane worsens. Their name is "accused, accursed." (30) The Kuseremane name was once a name so highly connected that it opened all doors. The same name has become a heavy burden on the family. It is an open secret that the family must be somehow connected to Rwandan genocide. "Now, tales have been added of a zealous servant instructed by an heir to wipe out the stain." (31) It is not exactly clear in the course of narration if the Kuseremane family bears sole blame for what has happened in Rwanda or if they do so, realize their guilt but everyone, even friends have become wary and are appalled as soon as they become aware of the family's name.

Finally, the Whispers have found human voices and it becomes even harder for the family in Kenyan exile to strengthen their supposedly promising contacts in Kenya and abroad. Back home in Rwanda, the family has lost its name as well as its influence. At first, it seems like it would be very easy to move to Europe, Boniface Kuseremane believes strongly that these whispers and then rumours of their guilt will not carry weight in Europe. In Kenya too, he believes that the Whispers being carried by the wind will "fall silent." (36) Even though only rumours and whispers exist, the weight on the family is quite heavy and this tells seriously on the family and greatly influences their existence in Kenya on a refugee status. The situation of these refugees in exile is a precarious one resulting in total collapse. The protagonist learns to make himself invisible so he does not stand out of the masses and make himself an easy target. He turns to quiet places in order to forget his real life. Now, he can understand why some things always remain unexpressed and remain "buried in silence." (13)Seeing that his own name is accused with a heinous crime and that in order to invoke, it is better for him and his family to remain silent about this subject. Even when he tries to adapt the situation, he slowly breaks down. He cries in secret and becomes unusually aggressive towards his wife Lune and his sister Chi-chi .It is unimaginable that his wife and sister had to become prostitutes for them to get their emigration papers. (29) When he should be taking care of the family he cannot because he feels that he is being taunted for his ineffectuality. (29) Kuseremane blames himself for the death of his sister and cannot blame his wife for prostituting herself. He decides to stay with his sister and mother in Kenya and "live in the silence and perform the rituals of return, for life." (36) This is a mirror of his desperation and acquiescent state of mind. Now that he wants to leave and can actually, finally leave, he thinks of the struggles and harassments he has experienced as a refugee. It is either he does not want to leave anymore because his former life has fallen into pieces; is inexistent, another life in another time and this now is his second life. (36)

Boniface Kuseremane is portrayed as an escapist who, when faced with an undeniable situation of need as refugee, prefers to circumscribe his own and his family status in the euphemistic terms of "visitors, tourists, people in transit, universal citizens with . . . an affinity to Europe." (16) He is reluctant to accept the unfortunate development of the situation but expresses hope; a hope that it seems is linked not only to the resolving of the awful and insecure state of affairs for himself and his family but a rather strong desire to run away from the whispers, horrifying visions and a mysterious, ever repeating uttering of his very own name, that haunt him day and night.

Relatively, in an early stage of denouement in which hope has not been completely lost, Kuseremane still sees a chance to escape the spell by leaving the continent: "soon we will be gone to Europe where the wind's weight of whispers does not matter; where the wind and all its suggestions have been obliterated." (19) Obviously, he is not only in political exile but emotional exile as well. He is thus trying to escape from concrete problems as well as the more abstract but seemingly more urgent problem: the whispers. This can also be seen as an escape from self. The whispers come from a voice within that carries the truth of having committed an egregious crime which he is unwilling to confess neither to himself nor to the reader. Though not clearly, Kuseremane's narration is structured in a desultory and blurring manner. This, to a large extent, hinders the reader in clearly construing the facts. Even at that, the story still reveals Kuseremane's complicity in the affairs of the genocide. The most apparent facts are his beating his wife and sister and the general pattern of shifting blames on third persons. Further discussion of this blurring effect will be highlighted in the subsection below on Kuseremane as an unreliable narrator.

To only read Kuseremane as that "Rwandan Tutsi aristocrat" is to perform an irresponsibly violent simplification of a character whose provenance is consciously problematical in the text; a simplification that with brutal irony perpetuates the simplified and racialised discursive binary of Tutsi/Hutu that partially enabled the 1994 genocide, and which continues in the news media and "common-sense" popular consciousness today. Within the story, although aspects of Kuseremane's precise origins remain elliptical and indeterminate, and this is partially because the narrative is a present tense depiction of his present condition, it is 
clear that throughout the story, and particularly during his early days in Nairobi, there are certain putative identity-anchors onto which Kuseremane is wont to arrogantly cling.

Kuseremane's anchors within the text, his misguided certainties, even toward the end of his decline, are these: he is a member of a divine-right royalty who at birth was "recognised by the priests as a man and a Prince"; he is a former senior diplomat; he is a successful neo-colonial elite partner in both a banking and gemstone business; he is a well-educated "universal citizen" with a Ph.D. in Diplomacy and a Masters in Geophysics. $(12,16)$ So firmly does he want to retain these aspects of his identity that even as this identity clearly unravels - something that the text's structural irony enables the reader to appreciate, while Kuseremane does not - and he is faced with an unhelpful and unsympathetic staff member at the American Embassy who denies him any rights to asylum since he cannot produce the correct papers, his having left his home country in a hurry, he still "want[s] to shout to the woman: I am Boniface Kuseremane, a prince, a diplomat." (17) Other clues in the text suggest the Kuseremanes' racial-ethnic and geographical "origins": they are at intervals described as being "very tall", "slender" and possessed of "high cheekbones." These pointers prompt the reader to recognise that Kuseremane is probably a Tutsi, even though the word "Tutsi" is not used in the text, for these are the physiological indicators that have been used since the days of John Hanning Speke and Henry Morton Stanley to racially define this Great Lakes group, and which have become commonly accepted even in the region itself, as we shall see. However, matters become complex and problematic as we continue to read Owuor's fiction, which is rooted in historical time, alongside the postcolonial history of the region. The time and the places and faces do not add up, and not as a consequence, as some might state, of Owuor's inadequate research.

Firstly, Kuseremane is implicated in the genocide (although the text leaves his real guilt ambiguous), and towards the end of the text his name has been added in his home country to the list of genocidaires;indeed, the "weight of whispers" in the story are these rumours of his improbable involvement that filter through to Kenya and that lead to him being ostracised by his fellow refugees and to that symbolic act of self-abnegation, his inability to utter his own name in public.

As a consequence of Kuseremane's royal lineage and physiological features, and the fact that there is genocide in his home country that has experienced the death of a president, we are almost obliged to take the simple option and conclude that he is a member of the Rwandan Tutsi Monarchy that was abolished just prior to the country's independence. And yet, the possibility that a Tutsi might have been involved in the genocide that victimised Tutsis and moderate Hutus in Rwanda is a nonsense bordering on the obscene; at least, the choice of only a Tutsi killer as central character by Owuor would have deflected blame from the real instigators, the "extreme Hutu", and have been a contribution to a damnable revisionist historiography. This, coupled with the near impossibility of Kuseremane having recently been a senior diplomat, bearing in mind that Habyarimana's Hutu regime in Rwanda could boast, only a token one Tutsi ambassador in the entire diplomatic service, creates confusion. (49) Avoiding falling into the liberal critical trap of reading Kuseremane as a real individual, we have to conclude that these are not mere inconsistencies of characterization that may be overlooked for the sake of a "good read", but rather that they are problems that cannot be resolved. In fact, the impossibility of Kuseremane's origins being what we are told they are, or what is heavily suggested by the text, is enough to draw attention to the fictionality of his "character", making him a version of Brian McHale's unreliable or "cancelled character", one who lacks integrity and coherent identity, and whose textual constructedness is laid bare (105). Consequently, the reader is forced to avoid a reading that might simply evince a uselessly sympathetic tear for the disenfranchised Kuseremane as a person, an approach that Owuor in one interview implies that she would not approve of, if only because in her conception Kuseremane is a dislikeable member of the neo-colonial African elite (46). Instead, we have to consider the function of this non-character, "Kuseremane". "Kuseremane's" own myths of origin and stable identity are, then, insupportable and seem to be increasingly delusional as the narrative processes, constructed only to be deconstructed in the postcolonial city and reformulated into that global victim, "The Refugee", by the discursive power of institutions such as foreign embassies, Kenyan lawlessness and those flat-character Kenyan shopkeepers and landlords who symbolise the tragedy of global capitalism. Owuor's fiction discursively parallels this with the insidious historical postcolonial construction of the Rwandan Tutsi as an ethnic group - an identity construction that, as mentioned, partially enabled the genocide, and which led to Tutsi being the majority of refugees who were forced to flee Rwanda at the time "Kuseremane" does. By problematising the fictional individual, "Kuseremane", and by featuring by implication the historical genocide as the serious issue that cannot be immorally played with and, in traditional fashion, “enjoyed as a good yarn", Owuor's text obliges us to focus on the problematic history of his Tutsi origin.

\section{REFERENCES}

1. Achebe, C. (2012). There Was A Country: a Personaal History of Biafra. London: Penguin Books Limited. 
2. Adichie, C. N. (2006). Half of a Yellow Sun. Lagos: Farafina Books.

3. Arnold, M. (1968). The function of Criticism at Present Time, Victorian Poetry and Poetics. Boston: Houghton Mfflin Company.

4. La Driere, J. C. (1953). Directions in contemporary Criticism. Wisconsin: the Bruce Publishing Company.
5. Ker, I. D. (2004). Literature and Society in Africa Ibadan; Spectrum Books Limited.

6. Nnolin, C. (2010). Issues in African Literature. Lagos: Malthouse Press Limited.

7. Ogbedu, M. O. (2017). Social Realism in African Prose Fictions. N. P, Abuja.

8. Omotosho, K. (2009). Achebe or Soyinka: A study in Contrast. Ibadan: Bookcraft. 